\title{
Evaluation of Bread Wheat (Triticum aestivum L.) Genotypes for Drought Tolerance through Selection Indices
}

\author{
Jawed Aslam Khyber ${ }^{1}$, Faiza Soomro ${ }^{1}$, Wahid Dino Sipio ${ }^{1}$, Abdul Wahid \\ Baloch $^{1}$, Jay Kumar Soothar ${ }^{1}$, Mukesh Kumar Soothar ${ }^{2,3 *}$, Zahid Ali $^{4}$
}

${ }^{1}$ Department of Plant Breeding and Genetics, Sindh Agriculture University Tandojam, Pakistan

${ }^{2}$ Farmland Irrigation Research Institute, Chinese Academy of Agricultural Sciences, Xinxiang 453000, China

${ }^{3}$ Department of Soil Science, Sindh Agriculture University Tandojam, Pakistan

${ }^{4}$ Department of Agronomy, Sindh Agriculture University Tandojam, Pakistan

mukeshksootar@gmail.com

Keywords: Wheat, selection indices, physiological traits, drought.

\begin{abstract}
The current study was planned to identify drought tolerance bread wheat genotypes based on physiological and yield traits. In this context, a set of 12 genotypes (Sarsabz, NIA-Sundar, NIAAmber, Sassui, Khirman, Marvi-2000, NIA-Sarang, Kiran-95, NIA-Sunheri, Bhittai, Bathoor-08 and Tatara) were evaluated under optimum and water stress conditions. Mean squares from analysis of variance exhibited that genotypes, treatments and genotype $\mathrm{x}$ treatment interaction showed significant differences $(\mathrm{P}<0.05)$ for majority of the studied traits, indicating that there is significant variations are existing for physio-yield traits; therefore these genotypes may be preferred for further breeding programs with respect to drought stress. Regarding reduction percentage of genotypes under drought stress against optimum water conditions, the minimum reduction was observed in Bathoor-08 for spike length and flag leaf area, Kiran-95 for grain yield plant, NIA-Sundar for seed index, Marvi-2000 for relative water content, Sarsabz for grains spike, whereas maximum but desirable reduction of stomatal dimension and density was displayed by Sarsabz and Tatara under water stress conditions, respectively. On the basis of drought tolerant indices, the genotypes Kiran95, NIA-Sundar and Sarsabz showed lower values for tolerance index (TOL), trait stability index (TSI) and stress susceptibility (SSI), nevertheless, it is believed that lower values of these indices show the less reduction in yield and its related traits due to water stress conditions hence can be tagged as tolerant genotypes for drought. Correlation results revealed that MP, SSI, TOL and TSI indices were correlated with grain yield under two conditions and they can be the appropriate indices for screening wheat genotypes.
\end{abstract}

\section{Introduction}

Wheat is the world most important cereal crop in terms of area and production. It has been grown in a wide range of arid and semi-arid regions, where due to rainfall fluctuations in rain-fed regions, drought occurs frequently [1]. Nowadays, in most countries wheat is the major staple food for people, because it provides more than $20 \%$ of the needed energy of the population in the world [2].

From all the stresses either biotic or abiotic factors, it is drought which plays a significant role in the reduction of wheat production and performance upto a great extent. It is recognized that almost $50 \%$ of wheat cultivated land in the developing countries is under rainfed condition [3]. Drought has been a worldwide problem constraining global crop production seriously [4]. Drought, being the important environmental stress, severely impairs plant growth and development [5]. The severe effects of drought are numerous, including: reduction in the crop yield, unavailability of fodder and feed. Wheat yield is reduced by $57 \%$ from their potential because of drought spell on about 60 million hectare in the developing world [6]. Water stress at all stages of plant growth affects the grain yield but when it takes place in critical stages of growth, grain yield is sharply 
decreased [7]. The Province Sindh is located in south eastern Pakistan. One of the most notable features of this province is the Indus River. This River is the primary source of economic potential in the province yet it is also the source of the province's greatest hazard: flood. The second major hazard is drought which reflects the province's dry climate and semi-arid environment. In the past 5 years, both flood and drought have affected Sindh Province so badly, including the study area of Jamshoro, Umerkot and Tharparkar Districts. Three consecutive years of flood emergencies (20102013) were then followed by a severe, two-year drought (2013-2015). Tharparkar and Umerkot Districts were particularly affected by the drought due to their desert environment [8]. Considering the importance of drought in wheat yield reduction, a number of breeding strategies and methods have been formulated. To overcome the drought stress problem, to develop new varieties which can perform better under stress conditions. Genetic gain through the use of empirical or conventional breeding approach is still useful [9].

To differentiate between drought resistant genotypes, several selection indices have been suggested on the basis of a mathematical relationship between favorable and stressed conditions [10, 11]. Tolerance (TOL) [12, 13], mean productivity (MP) [12], stress susceptibility index (SSI) [14], harmonic mean (HM) [15], geometric mean productivity (GMP) and stress tolerance index (STI) [16]. All of these have been employed under various conditions. Physio-yield traits have great importance in order to understand the complex responses of plants to water deficiency and to sustain the plant productivity. In this context, the current study was designed to observe the response of physiological and morphological traits of bread wheat genotypes through selection indices under water stress conditions.

\section{Materials \& Methods}

The experiment was conducted at Experimental Field, Department of Plant Breeding \& Genetics, Sindh Agriculture University, Tandojam, Pakistan. The experiment was laid out in having randomized complete block design with three replications with factorial arrangements during mid November (Rabi season), 2016-17 in order to assess the response of wheat genotypes for terminal drought tolerance. The water level was considered as the main factor, while varieties as sub-factor. The irrigation regimes with no-stress condition received six normal number of irrigations without any water stress. While in water stress, stress was applied at flowering from initiation of anthesis till the grain formation. Each variety was sown with five rows of $4 \mathrm{~m}$ length at $30 \mathrm{~cm}$ distances. Eleven wheat varieties viz; NIA-Sundar, NIA-Amber, Sassui, Khirman, Marvi-2000, NIA-Sarang, Kiran95, NIA-Sunhari, Bhittai and Bathoor-08 and Tatara are the wheat varieties of Nuclear Institute of Agriculture (NIA), Tandojam and Nuclear Institute of Food and Agriculture (NIFA) Peshawar, respectively. The above mentioned wheat varieties were studied under field conditions which were collected from NIA Tandojam, Sindh Pakistan. The following observations like, flag leaf area $\left(\mathrm{cm}^{2}\right)$, relative water content $(\%)$, stomatal density $\left(\mathrm{mm}^{-2}\right)$, stomatal dimension $(\mu \mathrm{m})$, spike length $(\mathrm{cm})$, grains spike ${ }^{-1}$ grain yield plant ${ }^{-1}(\mathrm{~g})$, seed index (1000-grain weight, g) were recorded.

The sowing was done by dibbling, keeping $20 \mathrm{~cm}$ space between plants and $30 \mathrm{~cm}$ between rows. Five plants were randomly selected and tagged from each replication. All the required cultural operations were adopted uniformly throughout the growing period as and when required. After collecting necessary data under field conditions, further observations were recorded at the laboratory. Flag leaf weight was weighed of five samples of each replication in $\mathrm{mg} / \mathrm{cm}^{2}$ and averaged the obtained data.

Relative water content (RWC \%) was determined according to [17] Gavuzzi et al. (1997); ten fully expended leaves were sampled from each of four replications at anthesis stage. The leaf sample were fresh weighed (FW), wilted for 4 hours in distilled water, and after four hours, the leaves were weighed to take turgid weight (Tw), and after this, these leaves were oven dried for 24 hour at $72^{\circ} \mathrm{C}$ to obtain dry weight (DW). The relative water content was calculated as under:

$\mathrm{RWC} \%=($ fresh weight-dry weight $) /$ (turgid weight-dry weight $) \times 100$. 
After the boot stage, the fully expanded flag leaves were selected for stomatal studies. The abaxial (lower) epidermis of the leaves was carefully smeared with nail varnish in the mid-area between the central vein and the leaf edge and the varnish was allowed to set for approximately 20 min. The thin film of nail polish (measuring approximately $10-20 \mathrm{~mm}$ ) was peeled-off from the leaf surface, mounted on a glass slide, immediately covered with a cover slip, and then lightly pressed with fine point tweezers. The density of stomata (number per $\mathrm{mm}^{-2}$ ) and their size $(\mu \mathrm{m})$ for each filmstrip were determined after taking pictures under 10x magnifications with a photomicroscope. The length of the spike was measured with the help of measuring tape, the resulting height was recorded as spike length in $(\mathrm{cm})$. The total numbers of seeds in main spike were counted and data were recorded as grains spike ${ }^{-1}$. After harvesting, each plant was threshed separately by hand and grains were weighed on electronic digital balance and yield plant ${ }^{-1}$ was weighed in grams. Thousand seeds were counted at random and weighed in grams in the laboratories with the help of electronic digital balance.

\section{Statistical Analysis}

Data was statistically analysed using analysis of variance according to [18] Gomez and Gomez (1984), while least significant differences (LSD) test was used to compare the mean differences. The following selection indices were used to isolate drought tolerant bread wheat genotypes.

1. Tolerance index (TOL) by Rosielle and Hambling (1981)

$$
\mathrm{TOL}=\quad \mathrm{Yp}-\mathrm{Ys}
$$

2. Mean productivity (MP) by Rosielle and Hambling (1981)

$\mathrm{MP}=\underline{\mathrm{Ys}+\mathrm{Y}}$

3. Trait stability index (TSI) by Bouslama and Schapaugh (1984)

$\mathrm{TSI}=\frac{\mathrm{Ys}}{\mathrm{Yp}}$

4. Stress susceptibility index (SSI) by Fischer and Maurer (1978)

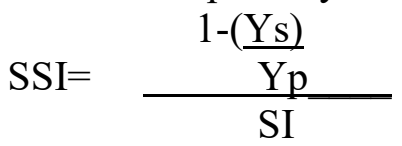

\section{Results}

Mean squares from analyses of variances (Table 1) shows that water stress revealed significant effect on relative water content, stomatal dimension, stomatal density, specific flag leaf weight, spike length, grains spike ${ }^{-1}$, grain yield plant $^{-1}$ (g)and seed index. There also existed significant differences among the genotypes and treatments for all the physiological and yield traits observed that can help breeders to select drought tolerant genotypes on the basis of one or more morpho-physiological attributes. The mean squares due to genotype $\mathrm{x}$ treatment interaction were also significant for almost all the traits except stomatal dimension, stomatal density, spike length and grains spike ${ }^{-1}$. The significance of genotype $\mathrm{x}$ treatment interaction indicates that the genotypes performed variable over the stress treatment. These interactions could help breeders to select the best performing genotypes based on one or more desirable drought tolerant indicators. 
Table 1. Mean squares from analyses of variance for various morpho-physiological traits of wheat genotypes

\begin{tabular}{|c|c|c|c|c|c|}
\hline \multirow[b]{2}{*}{ Characters } & \multicolumn{5}{|c|}{ Mean squares } \\
\hline & $\begin{array}{l}\text { Replications } \\
\quad(D . F .=2)\end{array}$ & $\begin{array}{l}\text { Genotypes } \\
(\text { D.F.= 11) }\end{array}$ & $\begin{array}{c}\text { Treatments } \\
\text { (D.F.= 1) }\end{array}$ & $\begin{array}{c}\text { G x T } \\
(D . F .=11)\end{array}$ & $\begin{array}{c}\text { Error } \\
(D . F .=46)\end{array}$ \\
\hline Relative water content & 11.33 & $42.97^{* *}$ & $7426.74^{* *}$ & $55.35^{* *}$ & 10.27 \\
\hline Stomatal dimension & 228.10 & $18331.3^{* *}$ & $3478.60^{* *}$ & $53.60^{\mathrm{ns}}$ & 181.60 \\
\hline Stomatal density & 1.14 & $1168.02^{* *}$ & $1775.09^{* *}$ & $3.16^{\mathrm{ns}}$ & 155.10 \\
\hline Specific flag leaf weight & 0.13 & $5.93^{* *}$ & $24.08^{* *}$ & $1.126^{* *}$ & 0.17 \\
\hline Spike length & 3.23 & $4.38^{* *}$ & $12.25^{* *}$ & $0.18^{\mathrm{ns}}$ & 0.25 \\
\hline Grains spike $^{-1}$ & 0.87 & $200.52^{* *}$ & $86.90^{* *}$ & $1.32^{\mathrm{ns}}$ & 2.44 \\
\hline Grain yield plant $^{-1}$ & 4.21 & $13.86^{* *}$ & $1284.57^{* *}$ & $13.54^{* *}$ & 1.03 \\
\hline Seed index & 5.87 & $70.12^{* *}$ & $8335.34^{* *}$ & $50.44^{* *}$ & 1.59 \\
\hline
\end{tabular}

Relative water content is an important parameter of water stress in leaves. In controlled conditions, the relative water content varied from 80.95 to $93.38 \%$, whereas in stress, the values were 54.18 to $69.85 \%$; however, the average decrease of -20.31 in relative water content was noticed due to water stress (Table 2). The top three genotypes having higher percentage of relative water content in stress condition were NIA-Amber (69.85\%), Tatara (69.80\%) and Marvi-2000 (68.54\%), while the lowest relative water content was noticed in NIA-Sunheri (54.18\%), Sarsabz (60.88\%), and NIA-Sarang $(61.55 \%)$.

\section{Stomatal dimension $(\mu \mathrm{m})$}

In non-stress, the range of stomatal dimension was estimated as 317.26 to $497.52(\mu \mathrm{m})$, while in stress it was 295.48 to $485.59(\mu \mathrm{m})$. The average water stress caused $-13.90(\mu \mathrm{m}) /$ slide. Among all the genotypes, maximum stomatal dimension of 497.52, 488.42 and $468.28(\mu \mathrm{m})$ were observed by NIA-Sundar, Tatara, and Marvi-2000 in non-stress conditions, respectively (Table 2). The lowest values were observed in the genotypes NIA-Amber (295.48), followed by Khirman (347.58) and Bathoor-08 (381.23).

Table 2. Mean performance of Relative water content (\%) and stomatal dimension $(\mu \mathrm{m})$ of wheat genotypes grown under stress and non-stress conditions

\begin{tabular}{|c|c|c|c|c|c|c|}
\hline \multirow{2}{*}{ Genotypes } & \multicolumn{2}{|c|}{$\begin{array}{l}\text { Relative water content } \\
(\%)\end{array}$} & \multirow{2}{*}{ R.D.* } & \multicolumn{2}{|c|}{$\begin{array}{c}\text { Stomatal dimension } \\
(\mu \mathrm{m})\end{array}$} & \multirow{2}{*}{ R.D.* } \\
\hline & $\begin{array}{c}\text { Non- } \\
\text { stress }\end{array}$ & $\begin{array}{c}\text { Drought } \\
\text { stress }\end{array}$ & & $\begin{array}{l}\text { Non- } \\
\text { stress }\end{array}$ & $\begin{array}{c}\text { Drought } \\
\text { stress }\end{array}$ & \\
\hline Sarsabz & 80.95 & 60.88 & -20.07 & 463.98 & 440.38 & -23.59 \\
\hline NIA-Sundar & 93.38 & 64.06 & -29.32 & 497.52 & 485.59 & -11.93 \\
\hline NIA-Amber & 85.51 & 69.85 & -15.67 & 317.26 & 295.48 & -21.77 \\
\hline Sassui & 83.57 & 61.69 & -21.88 & 394.73 & 381.46 & -13.27 \\
\hline Khirman & 84.45 & 64.18 & -20.27 & 358.81 & 347.58 & -11.24 \\
\hline Marvi-2000 & 81.98 & 68.54 & -13.44 & 468.28 & 461.84 & -6.43 \\
\hline NIA-Sarang & 88.66 & 61.55 & -27.11 & 466.77 & 451.70 & -15.07 \\
\hline Kiran-95 & 85.39 & 63.10 & -22.28 & 428.29 & 409.08 & -19.21 \\
\hline NIA-Sunheri & 84.02 & 54.18 & -29.84 & 398.56 & 390.38 & -8.17 \\
\hline Bhittai & 84.05 & 68.51 & -15.54 & 400.75 & 395.63 & -5.13 \\
\hline Bathoor-08 & 82.69 & 65.85 & -16.85 & 393.15 & 381.23 & -11.92 \\
\hline Tatara & 81.30 & 69.80 & -11.50 & 488.42 & 469.34 & -19.08 \\
\hline Mean & 84.66 & 64.35 & -20.31 & 423.04 & 409.14 & -13.90 \\
\hline LSD at $5 \%(G)$ & \multicolumn{2}{|c|}{3.72} & & \multicolumn{2}{|c|}{15.66} & \\
\hline LSD at $5 \%(T)$ & \multicolumn{2}{|c|}{1.52} & & \multicolumn{2}{|c|}{6.39} & \\
\hline LSD at $5 \%(\mathrm{G} \times \mathrm{T})$ & \multicolumn{2}{|c|}{5.26} & & \multicolumn{2}{|c|}{22.14} & \\
\hline
\end{tabular}

R.D* $=$ Relative decrease due to stress 


\section{Stomatal density $\left(\mathrm{mm}^{-2}\right)$}

In non-stress, stomatal density was varied from 99.33 to $49.50\left(\mathrm{~mm}^{-2}\right)$, whereas in the stress conditions, it ranges from 89.83 to $41.00\left(\mathrm{~mm}^{-2}\right)$. However, the average reduction of $-7.36\left(\mathrm{~mm}^{-2}\right)$ in stomatal density was noticed due to water stress (Table 3 ). Top three genotypes retaining higher range of stomatal density was Khirman $\left(99.33 \mathrm{~mm}^{-2}\right)$, Sarsabz $\left(89.00 \mathrm{~mm}^{-2}\right)$ and NIA-Amber $(76.83$ $\mathrm{mm}^{-2}$ ) in non-stress, while in stress, the values of stomatal density were $89.83,78.50$ and $78.50 \mathrm{~mm}^{-}$ 2 found in the bread wheat genotypes Khirman, Sarsabz and Tatara, respectively.

\section{Specific flag leaf weight $\left(\mathrm{mg} / \mathrm{cm}^{2}\right)$}

Reduction in the specific flag leaf weight by water stress is an important cause of reduced crop yield. On an average, a substantial decline of $-1.15\left(\mathrm{mg} / \mathrm{cm}^{2}\right)$ was noticed due to water stress. Yet, the minimum effect of water stress was observed in NIA-Sarang, Bathoor-08 and NIA-Amber with reduced values of $-0.63,-1.1$ and $-1.14 \mathrm{mg} / \mathrm{cm}^{2}$, respectively. Against maximum effect of -2.27 , -1.81 and -1.80, this was observed in NIA-Sundar, Kiran-95 and Khirman, respectively (Table 3).

Table 3. Mean performance of Stomatal density $\left(\mathrm{mm}^{-2}\right)$ and Specific flag leaf weight $\left(\mathrm{mg} / \mathrm{cm}^{2}\right)$ of wheat genotypes grown under stress and non-stress conditions

\begin{tabular}{|c|c|c|c|c|c|c|}
\hline \multirow{2}{*}{ Genotypes } & \multicolumn{2}{|c|}{$\begin{array}{l}\text { Stomatal density }\left(\mathrm{mm}^{-}\right. \\
\left.{ }^{-}\right)\end{array}$} & \multirow{2}{*}{ R.D.* } & \multicolumn{2}{|c|}{$\begin{array}{l}\text { Specific flag leaf } \\
\text { weight }\left(\mathrm{mg} / \mathrm{cm}^{2}\right)\end{array}$} & \multirow{2}{*}{ R.D.* } \\
\hline & $\begin{array}{l}\text { Non- } \\
\text { stress }\end{array}$ & $\begin{array}{l}\text { Drought } \\
\text { stress }\end{array}$ & & $\begin{array}{l}\text { Non- } \\
\text { stress }\end{array}$ & $\begin{array}{l}\text { Drought } \\
\text { stress }\end{array}$ & \\
\hline Sarsabz & 89.00 & 78.50 & -10.50 & 3.95 & 2.72 & -1.23 \\
\hline NIA-Sundar & 72.00 & 61.50 & -10.50 & 5.99 & 3.72 & -2.27 \\
\hline NIA-Amber & 76.83 & 66.67 & -10.16 & 4.75 & 3.61 & -1.14 \\
\hline Sassui & 59.67 & 52.17 & -7.50 & 5.20 & 4.06 & -1.14 \\
\hline Khirman & 99.33 & 89.83 & -9.50 & 4.52 & 2.72 & -1.80 \\
\hline Marvi-2000 & 49.50 & 41.00 & -8.50 & 3.10 & 4.34 & -1.24 \\
\hline NIA-Sarang & 58.50 & 47.50 & -11.00 & 4.88 & 4.25 & -0.63 \\
\hline Kiran-95 & 75.33 & 63.83 & -11.50 & 7.93 & 6.12 & -1.81 \\
\hline NIA-Sunheri & 71.50 & 63.00 & -8.50 & 4.29 & 3.05 & -1.24 \\
\hline Bhittai & 72.17 & 63.33 & -8.84 & 4.83 & 3.56 & -1.27 \\
\hline Bathoor-08 & 60.17 & 50.17 & -1.00 & 4.37 & 3.27 & -1.10 \\
\hline Tatara & 60.33 & 78.50 & -18.17 & 5.90 & 4.38 & -1.52 \\
\hline Mean & 70.36 & 63.00 & -7.36 & 4.97 & 3.81 & -1.15 \\
\hline LSD at $5 \%(\mathrm{G})$ & \multicolumn{2}{|c|}{2.13} & & \multicolumn{2}{|c|}{0.49} & \\
\hline LSD at $5 \%(\mathrm{~T})$ & \multicolumn{2}{|c|}{0.87} & & \multicolumn{2}{|c|}{0.20} & \\
\hline LSD at $5 \%(\mathrm{G} \times \mathrm{T})$ & \multicolumn{2}{|c|}{3.01} & & \multicolumn{2}{|c|}{0.69} & \\
\hline
\end{tabular}

R.D* $=$ Relative decrease due to stress

\section{Spike length (cm)}

In stress, the spike length was observed from 8.53 to $11.00 \mathrm{~cm}$, while in non-stress the spike length was measured from 8.97 to $11.47 \mathrm{~cm}$. On an average, water stress caused $-0.82 \mathrm{~cm}$ decreased in spike length. Among all the genotypes, the maximum spike length of 11.47, 11.33 and $11.20 \mathrm{~cm}$ was measured by Kiran-95, Sassui and Marvi-2000 in non-stress, respectively (Table 4). Whereas in stress, the genotype NIA-Sunheri $(11.00 \mathrm{~cm})$, Bhittai $(10.80 \mathrm{~cm})$ and Tatara $(10.63 \mathrm{~cm})$ maintained their top rank order by producing higher spike length, hence proved to be drought tolerant genotypes.

\section{Grains spike $e^{-1}$}

In non-stress, the number of grains spike ${ }^{-1}$ ranged between 38.53 and 58.0, while in stress varied from 37.07 to 54.97. Averagely, water stress caused -2.19 grains declined in grains spike ${ }^{-1}$. From the genotypes, the highest number of grains spike ${ }^{-1}$ was obtained from Bhittai (58.00) followed by Tatara (57.40) and Khirman (56.60) in non-stress (Table 4). Whereas in stress, the genotypes Bhittai (54.97), Tatara (54.50) and Khirman (54.40) retained their position on first, 
second, and third respectively, and on the fourth position, it was Sassui (53.73), therefore, proved as drought tolerant genotypes.

Table 4. Mean performance for spike length $(\mathrm{cm})$ and grains spike ${ }^{-1}$ of wheat genotype grown under non-stress and water stress at initiation of anthesis

\begin{tabular}{|c|c|c|c|c|c|c|}
\hline \multirow[b]{2}{*}{ Genotypes } & \multicolumn{2}{|c|}{ Spike length $(\mathrm{cm})$} & \multirow[b]{2}{*}{ R.D.* } & \multicolumn{2}{|c|}{ Grains spike $^{-1}$} & \multirow[b]{2}{*}{ R.D.* } \\
\hline & $\begin{array}{l}\text { Non- } \\
\text { stress }\end{array}$ & $\begin{array}{l}\text { Drought } \\
\text { stress }\end{array}$ & & $\begin{array}{l}\text { Non- } \\
\text { stress }\end{array}$ & $\begin{array}{l}\text { Drought } \\
\text { stress }\end{array}$ & \\
\hline Sarsabz & 11.10 & 9.93 & -1.17 & 41.97 & 41.07 & -0.90 \\
\hline NIA-Sundar & 8.97 & 8.53 & -0.44 & 52.13 & 50.47 & -1.66 \\
\hline NIA-Amber & 9.73 & 8.87 & -0.86 & 50.40 & 49.07 & -1.33 \\
\hline Sassui & 11.33 & 9.60 & -1.73 & 55.80 & 53.73 & -2.07 \\
\hline Khirman & 9.80 & 9.20 & -0.60 & 56.60 & 54.40 & -2.20 \\
\hline Marvi-2000 & 11.20 & 10.47 & -0.73 & 53.20 & 50.30 & -2.90 \\
\hline NIA-Sarang & 10.07 & 9.47 & -0.60 & 54.73 & 52.93 & -1.80 \\
\hline Kiran-95 & 11.47 & 10.47 & -1.00 & 54.23 & 49.93 & -4.30 \\
\hline NIA-Sunheri & 11.80 & 11.00 & -0.80 & 50.07 & 48.27 & -1.80 \\
\hline Bhittai & 11.47 & 10.80 & -0.67 & 58.00 & 54.97 & -3.03 \\
\hline Bathoor-08 & 9.87 & 9.40 & -0.47 & 38.53 & 37.07 & -1.46 \\
\hline Tatara & 11.47 & 10.63 & -0.84 & 57.40 & 54.50 & -2.90 \\
\hline Mean & 10.69 & 9.86 & -0.82 & 51.92 & 49.72 & -2.19 \\
\hline LSD at $5 \%(\mathrm{G})$ & \multicolumn{2}{|c|}{0.58} & & \multicolumn{2}{|c|}{1.81} & \\
\hline LSD at $5 \%(\mathrm{~T})$ & \multicolumn{2}{|c|}{0.23} & & \multicolumn{2}{|c|}{0.74} & \\
\hline LSD at $5 \%(\mathrm{G} \times \mathrm{T})$ & \multicolumn{2}{|c|}{0.82} & & \multicolumn{2}{|c|}{2.56} & \\
\hline
\end{tabular}

R.D* $=$ Relative decrease due to stress

\section{Grain yield plant ${ }^{-1}(\mathrm{~g})$}

Grain yield plant ${ }^{-1}$ is the final result of all morphological and physiological responses of genotypes to drought stress condition. The average decrease noticed was $-8.44 \mathrm{~g}$ due to water stress (Table 5). The highest grain yield plant ${ }^{-1}$ was produced by Bhittai, NIA-Sundar and Sassui with grain yield values of $24.45,22.42,21.98 \mathrm{~g}$, respectively, in controlled condition, whereas, the cultivar Marvi-2000, Kiran-95, NIA-Sunheri and NIA-Sarang gave 12.02, 11.92, 11.63 and 11.62 g, respectively in water stress; therefore, they retained higher yields with lower decrease in drought condition.

\section{Seed index (1000-grain wt., g)}

In non-stress, the average seed index was $44.01 \mathrm{~g}$, whereas in drought condition, it was 22.49 g. On an average, water stress caused -21.51 g reduction in 1000 grain weight (Table 5), whereas reduction in seed index was smaller in NIA-Sunheri (-10.92g), Sarsabz (-17.24g), and NIA-Amber (-18.01g), and considerable decrease was noticed in Kiran-95 (-34.31), Bathoor-08 (27.45) and Khirman (-24.23g).

Table 5. Mean performance for grain yield plant $\mathrm{t}^{-1}(\mathrm{~g})$ and seed index $(\mathrm{g})$ of wheat genotype grown under non-stress and water stress at initiation of anthesis.

\begin{tabular}{|c|c|c|c|c|c|c|}
\hline \multirow{2}{*}{ Genotypes } & \multicolumn{2}{|c|}{ Grain yield plant $^{-1}(\mathrm{~g})$} & \multirow{2}{*}{ R.D.* } & \multicolumn{2}{|c|}{$\begin{array}{l}\text { Seed index }(1000- \\
\text { grain weight, g) }\end{array}$} & \multirow{2}{*}{ R.D.* } \\
\hline & $\begin{array}{l}\text { Non- } \\
\text { stress }\end{array}$ & $\begin{array}{l}\text { Drought } \\
\text { stress }\end{array}$ & & $\begin{array}{l}\text { Non- } \\
\text { stress }\end{array}$ & $\begin{array}{l}\text { Drought } \\
\text { stress }\end{array}$ & \\
\hline Sarsabz & 16.57 & 11.41 & -5.16 & 45.56 & 28.32 & -17.24 \\
\hline NIA-Sundar & 22.42 & 10.27 & -12.15 & 44.74 & 25.59 & -19.15 \\
\hline NIA-Amber & 15.83 & 7.73 & -8.10 & 37.99 & 19.98 & -18.01 \\
\hline Sassui & 21.98 & 9.85 & -12.13 & 40.96 & 22.44 & -18.52 \\
\hline Khirman & 20.02 & 11.17 & -8.85 & 49.45 & 25.22 & -24.23 \\
\hline Marvi-2000 & 18.88 & 12.02 & -6.86 & 43.67 & 22.04 & -21.63 \\
\hline
\end{tabular}




\begin{tabular}{|c|c|c|c|c|c|c|}
\hline NIA-Sarang & 19.12 & 11.62 & -7.50 & 48.44 & 24.74 & -23.70 \\
\hline Kiran-95 & 16.18 & 11.92 & -4.26 & 51.07 & 16.76 & -34.31 \\
\hline NIA-Sunheri & 16.50 & 11.63 & -4.87 & 41.58 & 30.66 & -10.92 \\
\hline Bhittai & 24.45 & 10.84 & -13.61 & 39.18 & 18.57 & -20.61 \\
\hline Bathoor-08 & 18.43 & 9.47 & -8.96 & 41.07 & 13.62 & -27.45 \\
\hline Tatara & 20.36 & 11.44 & -8.92 & 44.45 & 22.00 & -22.45 \\
\hline Mean & 19.22 & 10.78 & -8.44 & 44.01 & 22.49 & -21.51 \\
\hline LSD at $5 \%(\mathrm{G})$ & \multicolumn{2}{|c|}{1.18} & & \multicolumn{2}{|c|}{1.46} & \\
\hline LSD at $5 \%(\mathrm{~T})$ & \multicolumn{2}{|c|}{0.48} & & \multicolumn{2}{|c|}{0.59} & \\
\hline LSD at $5 \%(\mathrm{G} \times \mathrm{T})$ & \multicolumn{2}{|c|}{1.66} & & \multicolumn{2}{|c|}{2.07} & \\
\hline
\end{tabular}

R.D* $=$ Relative decrease due to stress

\section{Drought Tolerance Indices}

\section{Comparing genotypes based on the resistance/tolerance indices}

To investigate suitable drought tolerance indices for screening the wheat genotypes under drought stress conditions, various indices were calculated based on grain yield under stressed and controlled conditions. Based on different indices, the results are as under:

\section{Tolerance (TOL)}

TOL was introduced by Rosielle and Hamblin (1981), they used this index to find out the difference in yield of genotypes under stress and non-stress condition. The genotypes with lower value of this index are more desirable. According to Table 6, the genotypes Kiran-95 (4.26), NIASunheri (4.87) and Sarsabz (5.16) pose lower values of TOL and these remained on the top of the position, respectively, while Bhittai (13.61), NIA-Sundar (12.15) and Sassui (12.13) retained the high values of TOL and are susceptible to drought conditions.

\section{Mean productivity (MP)}

The term mean productivity was coined by Rosielle and Hamblin (1981) [19], referring to the average yield of genotypes between stress and non-stress conditions. The genotypes with high values of MP were considered as more desirable. According to this index, the genotypes Bhittai (17.65), NIA-Sundar (16.35) and Sassui (15.91) were having higher values; on the other side, NIAAmber (11.78), Bathoor-08 (13.95), and Sarsabz (13.99) were having the lower values (Table 6).

\section{Trait stability index (TSI)}

It was suggested by [20] Bouslama and Schapaugh (1984) in order to evaluate the stability of genotypes in stress and non-stress conditions. The genotypes with higher values of TSI can be regarded as stable genotypes under stress and non-stress conditions. The genotype Kiran-95 (0.74), NIA-Sunheri (0.70) and Sarsabz (0.69) were having higher values, thus ranked as 1, 2, and 3, respectively and are regarded as stable genotypes under stress and non-stress conditions (Table 6).

\section{Stress susceptible index (SSI)}

Stress susceptible index (SSI) was suggested by [14] Fisher and Maurer (1978) for the measurement of yield stability. However, this index suffers from apprehensions of the change in both potential and actual yield in erratic environments. The genotypes with $\mathrm{SSI}<1$ are more resistant to drought stress conditions. Under stress and non-stress conditions, the highly resistant genotypes based on SSI were Kiran-95 (0.60), NIA-Sunheri (0.67) and Sarsabz (0.71). While, the genotypes Bhittai (1.27), Sassui (1.26) and NIA-Sundar (1.23) were most susceptible ones (Table 6). 
Table 6. Mean values and ranking order of different selection indices based on grain yield plant under optimum water conditions and drought stress conditions

\begin{tabular}{|l|c|c|c|c|c|c|c|c|}
\hline \multirow{2}{*}{ Genotypes } & \multicolumn{2}{|c|}{ TOL } & \multicolumn{2}{c|}{ MP } & \multicolumn{2}{c|}{ TSI } & \multicolumn{2}{c|}{ SSI } \\
\cline { 2 - 10 } & Value & Rank & Value & Rank & Value & Rank & Value & Rank \\
\hline Sarsabz & 5.16 & 3 & 13.99 & 10 & 0.69 & 3 & 0.71 & 3 \\
\hline NIA-Sundar & 12.15 & 11 & 16.35 & 2 & 0.46 & 10 & 1.23 & 10 \\
\hline NIA-Amber & 8.10 & 6 & 11.78 & 12 & 0.49 & 9 & 1.16 & 9 \\
\hline Sassui & 12.13 & 10 & 15.91 & 3 & 0.45 & 11 & 1.26 & 11 \\
\hline Khirman & 8.85 & 7 & 15.60 & 5 & 0.56 & 6 & 1.01 & 7 \\
\hline Marvi-2000 & 6.86 & 4 & 15.45 & 6 & 0.64 & 4 & 0.83 & 4 \\
\hline NIA-Sarang & 7.50 & 5 & 15.37 & 7 & 0.61 & 5 & 0.89 & 5 \\
\hline Kiran-95 & 4.26 & 1 & 14.05 & 9 & 0.74 & 1 & 0.60 & 1 \\
\hline NIA-Sunheri & 4.87 & 2 & 14.06 & 8 & 0.70 & 2 & 0.67 & 2 \\
\hline Bhittai & 13.61 & 12 & 17.65 & 1 & 0.44 & 12 & 1.27 & 12 \\
\hline Bathoor-08 & 8.96 & 9 & 13.95 & 11 & 0.51 & 8 & 1.11 & 8 \\
\hline Tatara & 8.92 & 8 & 15.90 & 4 & 0.56 & 7 & 1.00 & 6 \\
\hline
\end{tabular}

$>$ Tolerance (TOL)

$>$ Mean Productivity (MP)

$>$ Trait Stability Index (TSI)

$>$ Stress Susceptibility Index (SSI).

\section{Correlations between drought tolerance indices}

The analyses of correlation between drought tolerant indices can be a good phenomenon for screening the genotypes, which are highly drought tolerant by the use of best selection indices. Among all the four selection indices calculated, grain yield in stress condition (YS) was nonsignificantly but negatively correlated with YP $\left(\mathrm{r}=-0.18^{*}\right)$, while YP was significantly and positively correlated with MP $\left(\mathrm{r}=0.93^{* *}\right)$, SSI $\left(\mathrm{r}=0.66^{*}\right)$ and TOL $\left(\mathrm{r}=0.81^{* *}\right)$, whereas YP was significantly and negatively associated with TSI $\left(\mathrm{r}=-0.66^{*}\right)$. The yield in stress (YS) showed negative and significant associations with SSI $\left(\mathrm{r}=-0.79^{* *}\right)$ and TOL $\left(\mathrm{r}=-0.68^{*}\right)$, while also revealed a positive and significant correlation with TSI $\left(\mathrm{r}=0.79^{* *}\right)$.TOL was significantly and positively associated with SSI $\left(\mathrm{r}=0.94^{* *}\right)$ and MP $\left(\mathrm{r}=0.63^{*}\right)$. TSI was non-significantly and negatively correlated with MP $\left(\mathrm{r}=-0.51^{\mathrm{ns}}\right)$ but significantly and negatively correlated with SSI $\left(\mathrm{r}=-0.99^{* *}\right)$ and TOL $(-0.94 * *)$.

Table 7. Pearson correlation coefficient (r) between various selection $\mathrm{n}$ indices

\begin{tabular}{|l|c|l|l|l|l|}
\hline Indices & YP & YS & MP & SSI & TOL \\
\hline YS & -0.18 & & & & \\
\hline MP & $0.93^{* *}$ & 0.03 & & & \\
\hline SSI & $0.66^{*}$ & $0.79^{* *}$ & 0.51 & & \\
\hline TOL & $0.81^{* *}$ & $0.68^{*}$ & $0.63^{*}$ & $0.94^{* *}$ & \\
\hline TSI & $-0.66^{*}$ & $0.79^{* *}$ & -0.51 & $-0.99^{* *}$ & $-0.94^{* *}$ \\
\hline
\end{tabular}

**,* $=$ Significant at 1 and $5 \%$ probability level

\section{Discussion}

Plant breeders work to improve the yield potential of wheat crop; however, the progress in increasing the yield in drought stress has been more difficult to get. In general, breeding for drought resistance involves aggregating good yield potential in non-stress and the selection of traits having high heritability that provides drought stress tolerance. Various morphological traits like tillers plant $^{-1}$, plant height, spike length, grains spike ${ }^{-1}$, yield plant ${ }^{-1}$ and seed index have been used in stress conditions to select the drought resistant wheat genotypes [21] (Jatoi et al., 2012). 
Mean squares of analyses of variance (Table 1) revealed that water stress caused a significant effect on relative water content, stomatal dimension, stomatal density, specific flag leaf weight, spike length, grains spike ${ }^{-1}$, grain yield plant ${ }^{-1}(\mathrm{~g})$ and seed index. There also existed significant differences among the genotypes for all the physiological and yield traits observed that can help breeders to select drought tolerant genotypes on the basis of one or more morphophysiological attributes. The mean squares due to genotype $\mathrm{x}$ treatment interaction were also significant for almost all the traits except stomatal dimension, stomatal density, spike length and grains spike ${ }^{-1}$. The significance of genotype $\mathrm{x}$ treatment interaction indicates that the genotypes performed phenotypic variability over the stress treatment. These interactions could help breeders to select the best performing genotypes based on one or more desirable drought tolerant indicators. [22] Munjal and Dhanda (2016) also reported significant differences among the genotypes over the environments and over the years and environments for majority of the traits revealed that the genotypes behaved differently in different environments.

Leaf relative water content is a more important indicator of water status than other water potential parameters under drought stress. During plant development, drought stress significantly reduced relative water content values [23] (Siddique et al., 2000). The top 3 genotypes having higher percentage of relative water content in stress condition were; NIA-Amber, Tatara and Marvi2000, while the lowest relative water content was noticed in NIA-Sunheri, Sarsabz and NIA-Sarang. These results show that $1^{\text {st }}$ group of genotypes were drought tolerant and the $2^{\text {nd }}$ being susceptible, and the remaining genotypes were moderately drought tolerant. These results were similar to the findings of [24] Aydin et al. (2008), who showed that water deficiency was found to reduce the relative water content in the leaves of the plant. Furthermore, Munjal and [22] Dhanda (2016) also reported that majority of these genotypes also performed significantly better for drought related traits, including relative water content. Regarding stomatal dimension among all the genotypes, maximum $(\mu \mathrm{m})$ were observed by NIA-Sundar, Tatara, and Marvi-2000 in non-stress conditions (Table 2). The lowest values were observed in the genotypes Nia-Amber, Khirman and Bathoor-08. These results show that first group of genotypes was drought susceptible and second as drought tolerant. The remaining genotypes were moderately drought tolerant. [25] Nastaran et al. (2009) also investigated the same results. Talking about stomatal density under water stress conditions, top three genotypes retaining higher range of stomatal density was Khirman, Sarsabz and Nia-amber, while the genotypes Sassui, Marvi-2000 and NIA-Sarang showed lowest values under moisture stress conditions and proved as drought tolerant genotypes. Similar type of results was also noticed by [26] Wang et al. (2016).

Reduction in the specific flag leaf weight by water stress is an important cause of reduced crop yield. On an average, a substantial decline was noticed due to water stress. Yet the minimum effect of water stress was observed in Nia-Sarang, Bathoor-08, Nia-Amber and Sassui; hence these genotypes may be considered as drought tolerant. [27] Amanullah (2015) observed the similar type of results. With respect to spike length, on an average, water stress caused $-0.82 \mathrm{~cm}$ decreased in spike length. Among all the genotypes, maximum spike length was given by Kiran-95, Sassui and marvi-200 in non-stress conditions, respectively (Table 4). Whereas in stress, the genotypes NIASunheri, Bhittai and Tatara maintained their rank order by producing longer spike length, hence proved to be drought tolerant genotypes. Considering grains spike, averagely water stress caused of -4.13 grains declined in grains spike ${ }^{-1}$. From the genotypes in stress conditions, the genotypes Bhittai Tatara and Khirman retained their position on first, second and third place, respectively and on fourth it was Sassui, therefore proved as drought tolerant genotypes. Similar findings were observed by [21] Jatoi et al. (2012) who reported that the drought tolerant genotypes gave relatively minimum reduction in yield on individual mean basis in stress condition. [28] Gadimov et al. (2009) demonstrated that drought stress resulted in reduced pollination and reduces the number of grains spike ${ }^{-1}$. [29] Garcia-del-Moral (2005) reported that moisture-deficit affected the number of seeds spike ${ }^{-1}$, consequently decreased grain yield.

Grain yield is the final result of all morphological and physiological responses of genotypes to drought stress condition. The average decrease noticed was $-8.44 \mathrm{~g}$ due to water stress (Table 5). 
The higher grain yield plant $^{-1}$ was produced by the cultivar marvi-2000, kiran-95, NIA-Sunheri, and NIA-Sarang in water stress; therefore, retained higher yields with less decrease in drought condition. Thus, these genotypes sustained the water stress by showing drought resistance against the other genotypes. The study of [30] Praba et al. (2009) stated that the reduction in the grain yield was recorded about $32 \%$ as compared to control due to drought. Similar findings were observed by [31] Sial et al. (2012) who reported that grain yield was also significantly reduced at severe water stress. [32] Bauder (2001) who observed that yield is greatly reduced in stress mostly when drought stress occurred during the heading or flowering and soft dough stages. Drought stress during maturity resulted in about $10 \%$ decrease in yield, while, moderate stress during the early vegetative period had essentially no effect on yield. According to [31] Ali (2011), growth of wheat grain is reduced depending upon the degree of water deficit and the rate of stress development, thereby limiting final wheat grain yield. Drought stress at the grain-filling period dramatically reduces grain yield [33] (Talebi et al., 2009). [34] Akram (2011) claimed that the sensitivity of grain yield depends upon the severity of stress and the stage when it is applied. Water deficit imposed at different stages of grain growth separately showed a significant reduction in grain yield.

Due to water stress, seed index reduced significantly, showing an average of $-21.51 \mathrm{~g}$ (Table 5), whereas reduction in seed index was smaller in NIA-Sunheri, Sarsabz, and Nia-amber and a considerable decrease was noticed in Kiran-95, Bathoor-08 and Khirman. The 1st group of genotypes was assumed as drought tolerant and 2 nd group as drought susceptible. 1000 kernel weight and weight of kernels spike ${ }^{-1}$ were more severely decreased by the deficiency of water i.e rate of dry matter accumulation and a number of kernels were highly decreased due to water stress [21] (Jatoi et al., 2012). [35] Kobota et al. (1992) declared that weight reduction of grain wheat is subsequent to water access reduction due to reduction in further transformation process of spike. Similar findings were observed by [31] Sial et al. (2012) who reported that the stress showed less reduction in seed index (1000-grain weight). Water stress reduced photosynthesis and ultimately resulted in reduced 1000-grain weight, grain yield, number of grains spike ${ }^{-1}$ and other yield contributing components [36] (Brisson and Casals, 2005).

Drought indices which provide a measure of drought based on loss of yield under droughtconditions in comparison to optimum conditions have been used for screening drought tolerant genotypes [37] (Mitra, 2001). These indices are either based on drought resistance or susceptibility of genotypes [16] (Fernandez, 1992). Drought resistance is defined by [38] Hall (1993) as the relative yield of a genotype compared to other genotypes subjected to the same drought stress. Drought susceptibility of a genotype is often measured as a function of the reduction in yield under drought stress [39] (Blum, 1988). On the basis of drought tolerant indices, the genotypes Kiran-95, NIA-Sundar and Sarsabz showed lower values for TOL, TSI and SSI; nevertheless, it is believed that lower values of these indices show the less reduction in yield and its related traits due to water stress conditions hence can be tagged as tolerant genotypes for drought. On the other hand, the genotype Bhittai remained on top with higher value for MP, it is interesting to know that this genotype showed outstanding performance in non-stress conditions, while showed very poor performance under water stress conditions, therefore, all three indices also confirmed its poor performance and remained in lower rank as shown by TOL, TSI and SSI. [40] Mevlut and Sait (2011) referred that the genotypes with high MP usually poses high difference of yield in two different conditions. [41] Muhammadi et al. (2011) utilized drought resistance indices on the basis of grain yield under end-season drought (Ys) and optimum (YN) conditions. Evaluation of MP, HARM, GM, STI, TOL, SSI, RDI, YSI and Yr indicated that late sowing (20 Nov) significantly decreased drought tolerance in all investigated genotypes. However, yield comparisons under optimum and terminal drought stress conditions revealed that promising lines (C-81-4, C-81-10, C81-14 and C-82-12) had better performance than local checks.

To determine the most desirable drought tolerance index, the correlation coefficient between Yp, Ys and other indices of drought tolerance were calculated. Most of the researchers stated that the best suitable index for drought tolerant genotypes is an index that is highly correlated with grain yield under both stress and optimum conditions [42] (Golabadi et al., 2006). Result revealed that 
MP, SSI, TOL and TSI indices that were correlated with grain yield under two conditions (Tables 7) and they can be the appropriate indices for screening wheat genotypes. These findings are in accordance with the results of [41] Mohammadi et al. (2011) in bread wheat. The significant correlations between quantitative drought resistance indices such as MP, GMP, STI and HM with yield in stress and non-stress conditions are consistent with those reported by [1] Mardeh et al. (2006) in bread wheat. [43] Khakwani et al. (2011) observed a positive and significant correlation of some yield components with GMP in wheat varieties. [41] Muhammadi et al. (2011) also observed that GM, STI, HARM, MP, YI and P indices correlated with grain yield under two conditions and during the both years.

\section{Conclusion}

Mean squares from analysis of variance showed that genotypes, treatments and genotype $\mathrm{x}$ treatment interaction showed significant differences $(\mathrm{P}<0.05)$ for majority of the studied traits. This indicates that there are significant variations are existing for physio-yield traits; therefore, these genotypes may be preferred for further breeding programs in respect to drought stress. Regarding reduction percentage of genotypes under drought stress against optimum water conditions, the minimum reduction was observed in Bathoor-08 for spike length and flag leaf area; Kiran-95 for grain yield plant; NIA-Sundar for seed index; Marvi-2000 for relative water content; Sarsabz for grains spike; whereas maximum but desirable reduction for stomatal dimension and density was displayed by Sarsabz and Tatara under water stress conditions. On the basis of drought tolerant indices, the genotypes Kiran-95, NIA-Sundar and Sarsabz showed lower values for TOL, TSI and SSI; nevertheless, it is believed that lower values of these indices show the less reduction in yield and its related traits due to water stress conditions hence can be tagged as tolerant genotypes for drought. Correlation results revealed that MP, SSI, TOL and TSI indices that were correlated with grain yield under two conditions and they can be the appropriate indices for screening wheat genotypes.

\section{References}

[1] Mardeh, A.S.S, A. Ahmadi, K. Poustini, V. Mohammadi, Evaluation of drought resistance indices under various environmental conditions, Field Crop Res. 98 (2006) 222-229.

[2] Bushuk, W, V.F. Rasper, Wheat production, properties and quality, Blackie Academic \& Professional. Glasgow. UK. (1994) 239.

[3] Reynolds, M, S. Nagarajan, M.A. Razzaque, O.A.A. Ageeb, Heat tolerance, In: Application of Physiology in Wheat Breeding (Eds.): Reynolds, M.P, J.I. Ortiz- Monasterio and A. Mc. Nab. Mexico, D.F.: CIMMYT. 2001 (2014) 124-135.

[4] Comas, L.H, S.R. Becker, V.M.V. Cruz, P.F. Byrne, D.A. Dierig, Root traits contributing to plant productivity under drought, Front. Plant Sci. 4 (2013) 1-16.

[5] Castroluna, A, O.M. Ruiz, A.M. Quiroga, H.E. Pedranzani, Effects of salinity and drought stress on germination, biomass and growth in three varieties of Medicago sativa L, Adv. Agri. Res. 18 (2014) 39-50.

[6] Hlavinka, P, M. Trnkaa, D. Semeradova, M. Dubrovsky, Z. Zaluda, M. Mozny, Effect of drought on yield variability of key crops in Czech Republic, Agric. Forest Met. 149 (2009) 431-442.

[7] Zamurrad, M, M. Tariq, F.H. Shah, A. Subhani, M. Ijaz, M.S. Iqbal, M. Koukab, Performance based evaluation of groundnut genotypes under medium rainfall conditions of Chakwal, J. Agri. Food Appl. Sci. 1(2013) 9-12.

[8] World Food Programme, Food and Agriculture Organization of the United Nations, Food Security Cluster Published on 31 Aug 2016. 
[9] Gupta, P.K, H.S. Balyan, V. Gahlaut, P. Kulwal, Phenotyping, genetic dissection, and breeding for drought and heat tolerance in common wheat: status and prospects, Plant Breed. Rev. 36 (2012) 85-168.

[10] Clarke, N.D, M. Kvaal, E. Seeberg, Cloning of Escherichia coli genes encoding 3methyladenine DNA glycosylases I and II, Mol. Gen. Genet. 197 (1984) 368-372.

[11] Huang, Approximate nonlinear output regulation based on the universal approximation theorem, Int. J. Robust Nonlinear Con. 10(5) (2000) 439-456.

[12] McCaig, T, J.M. Clarke,Excised-leaf water retention capability as an indicator of drought resistance of Triticum genotypes,Canadian J. Plant Sci.62(3) (1982) 571-578.

[13] Clarke, D, A. Bridle, H.Alan, B. Jack, O. Perley, A.Richard, A. Michael,Origin of the structures and polarization in the classical double 3C 219, Astrophysical J. 385 (1992) 173187.

[14] Fischer, R, R. Maurer, Drought Resistance in Spring Wheat Cultivars. I. Grain Yield Responses, Australian J. Agri. Res. 29 (1978) 897-912.

[15] Chakherchaman, S.A, H. Mostafaei, L. Imanparast, Evaluation of drought tolerance in lentil advanced genotypes in Ardabil region, Iran. J. Food Agri Envir. 7 (2009) 283-288.

[16] Fernandez, G.C.J., Effective selection criteria for assessing plant stress tolerance, Proceedings of the International Symposium on Adaptation of Vegetables and other Food Crops in Temperature and Water Stress. 13-16 (1992) 257-270.

[17] Gavuzzi, P., F. Rizza, M. Palumbo, R.G. Compaline, G.L. Ricciardi and B. Borghi, Evaluation of field and laboratory predication of drought and heat tolerance in winter cereals, Can, J. Plant. Sci., 77 (1997) 523-531.

[18] Gomez, K.A, A. A. Gomez, Statistics for Agricultural Research (2 ${ }^{\text {nd }}$ ed.), John Willey and Sons, New York. (1984).

[19] Rosielle, A.A, J. Hamblin, Theoretical aspects of selection for yield in stress and nonstress environments, Crop Sci. 21 (1981) 943-946.

[20] Bouslama, M, W.T. Schapaugh, Stress tolerance in soybean. Part 1: Evaluation of three screening techniques for heat and drought tolerance, Crop Sci. 24 (1984) 933-937.

[21] Jatoi, W.A, M.J Baloch, M.B Kumbhar, M.I Keerio, Heritability and correlation studies of morpho-physiological traits for drought tolerance in spring wheat, Pak. J. Agri. Vet. Sci, 28(2) (2012) 100-114.

[22] Munjal, R, S.S. Dhanda, Assessment of drought resistance in Indian wheat cultivars for morpho-physiological traits, J. Crop Breed. Genet. 2(1) (2016) 74-81.

[23] Siddique, M.R.B, A. Hamid, M.S. Islam, Drought stress effects on water relations of wheat, Bot. Bull. Acad. Sinica. 41 (2000) 35-39.

[24] Aydin, G, J. David, A. Inal,S. Coban,Influence of silicon on sunflower cultivars under drought stress, I: Growth, antioxidant mechanisms, and lipid peroxidation, J. Com. Soil Sci. Plant Ana.39 (13-14) (2008) 1885-1903.

[25] Nastaran, M, R. Fotovat,J. Saba,F. Jabbari,Variation of stomata dimensions and densities in tolerant and susceptible wheat cultivars under drought stress,J. Food Agri. Envir. 7(1) (2009) 215-219.

[26] Wang, S.G, S.S. Jia,D.C. Sun,H. Fan,X.P. Chang, R.L. Jing,Mapping QTLs for stomatal density and size under drought stress in wheat (Triticum aestivum L.), J. Integrative Agri. 15(9) (2016) 1955-1967. 
[27] Amanullah.,Specific leaf area and specific leaf weight in small grain crops wheat, rye, barley, and oats differ at various growth stages and NPK source, J. Plant Nut, 8(11) (2015)1694-1708.

[28] Gadimov, A. G, R. Shahryari, A. G. Garayeva, A perspective on humic substances as natural technological products with miraculous biological effect on crops, Tran. Inst. Micro. Azerbaijan Nat. Acad. Sci. 7 (2009)118-126.

[29] Garcia de Moral, L.F, Y. Rharrabti, S. Elhani, V. Martos, C. Royo,Yield formation in Mediterranean durum wheat under two contrasting water regimes based on path-coefficient analysis, Euphytica, 146 (2005) 203-212.

[30] Praba, M.L, J.E. Caims, R.C. Babu, H.R. Lafitte, Identification of physiological traits underline cultivar differences in drought tolerance in rice and wheat, J. Agron. Crop sci. 195 (2009) 30-46.

[31] Sial, M.A, K.A. Laghari, N.A. Panhwar, M.A. Arain, G.M. Baloch, Genetic improvement of drought tolerance in semi-dwarf wheat, Sci. Tech. and Dev. 31 (4) (2012) 335-340.

[32] Bauder, J., Irrigating with Limited Water Supplies. Montana State University Communications Services. Montana Hall. Bozeman, MT 59717 USA (2012).

[33] Talebi, R, F. Fayaz, A.M. Naji, Effective selection criteria for assessing drought stress tolerance, Gene. Appl. Plant Physio. 35 (2009) 64-74.

[34] Akram, M., Growth and yield components of wheat under water stress of different growth stages, Bangladesh J. Agri. Res. 36 (2011) 455-468.

[35] Kobota, T.J, A. Palta, N.C. Turner, Rate of development of post anthesis water deficits and grain filling of spring wheat, Crop Sci, 32 (1992) 1238-1242.

[36] Brisson N,M.L. Casals, Leaf dynamics and crop water status throughout the growing cycle of durum wheat crops grown in two contrasted water budget conditions, Agron. Sustain. Dev. 25 (2005) 151-158.

[37] Mitra, J, Genetics and genetic improvement of drought resistance in crop plants, Current Sci. 80 (2001) 758-762.

[38] Hall, A.E, Is dehydration tolerance relevant to genotypic differences in leaf senescence and crop adaptation to dry environments? In: Plant Responses to cellular dehydration during environmental stress, (Eds.): T.J. Close and E.A. Bray.(1993) pp. 1-10.

[39] Blum, A, Plant Breeding for Stress environments, CRC Press Florida, (1988) p. 212.

[40] Mevlut, A, C. Sait, Evaluation of drought tolerance indices for selection of Turkish oat (Avena sativa L.) land races under various environmental conditions, Zemdirbyste Agro. 98 (2) (2011) 157-166.

[41] Mohammadi, M, R. Karimizadeh, M. Abdipour, Evaluation of drought tolerance in bread wheat genotypes under dryland and supplemental irrigation conditions, Australian J. Crop Sci. 5(4) (2011) 487-493.

[42] Golabadi, M, A. Arzani, Mirmohammadi, S.A.M. Meibody, Assessment of drought tolerance in segregating in segregating Populations in durum wheat, African J. Agri. Res. 5 (2006) 162-171.

[43] Khakwani, A.A, M.D. Dennett, M. Munir, Drought tolerance screening of wheat varieties by inducing water stress conditions, Songklanakarin J. Sci. Technol. 33 (2011) 135-142. 